\title{
SiM
}

\section{Using Rangelands on the Web as a Teaching Resource}

\author{
By John Tanaka, Barbara Hutchinson, Merrita Fraker-Marble, Rachel Frost, \\ Karen Launchbaugh, and Mel George
}

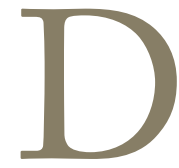

o your students go to Wikipedia for their reference material? Do they know where the library is and how to use it? Do they do general searches of the internet and spew forth whatever they find as facts? Do you wish there were better sources of information on rangelands to which you could direct them? We might just have a solution for you!

Over the past several years, groups of rangeland educators and subject-matter librarians have been collaborating on a variety of on-line projects. These different activities have been brought together under the banner of The Rangelands Partnership. Although the partnership has gone through several iterations over the years, this name seems to be the most allencompassing. In a recent article in Rangelands, each of the tools was described. ${ }^{1}$ In this article, we will provide you with a brief synopsis of the tools, discuss reusable teaching and learning objects, and focus on how those tools might be used in a teaching and learning setting. Although each of these tools is in various stages of "completion," they can all be accessed by typing in the Web address, and many of the functions are operating fully. The tools we will highlight are Rangelands West, ${ }^{\mathrm{i}}$ Global Rangelands, ii eXtension Rangelands, iii Range Science Information System, ${ }^{\text {iv }}$ and reusable teaching/learning object Web sites. ${ }^{v}$ These were each highlighted at a recent SRM hands-on workshop in Spokane. Each of these tools can have a role in teaching or student learning. You should look at the recent Rangelands article for more specific information, or better yet, just go to each Web site and look around.

\section{On-Line Rangelands Information Tools}

Rangelands West (RW) and Global Rangelands (GR) are similar Web sites with different geographic coverage. Rangelands West is the main portal to vetted information on all aspects of western US rangeland ecology and management. Linked to the 19 regional sites are state-based sites put together by state extension specialists and subject-matter librar-

\footnotetext{
i http://rangelandswest.org.

"http://globalrangelands.org.

iii http://extension.org/rangelands/.

${ }^{\text {iv }} \mathrm{http}: / /$ rangescience.info

$\checkmark$ See, for example, the World Rangelands Learning Experience (Wrangle), http://wrangle1.com.
}

ians. Although all the states contribute to the regional Web site, individual state sites might also have information specific and important to that state. Global Rangelands is the latest endeavor that seeks to include rangeland information from around the world. It has started with the United Nations Food and Agriculture Organization (FAO) publications related to rangelands and partners from Australia and Mexico, with more to come. Currently, the Global Rangelands/Rangelands West database includes more than 10,000 full-text articles and reports, as well as thousands more unique pages of content on a variety of hot-topic issues. There is an interactive world map of global rangeland ecosystems in progress as well as complete descriptions of each ecosystem, along with related resources and videos. Interested users can search the database as simply as a Google search, but also can easily limit searches by subtopics, geographic region, date, and author.

All of the state Cooperative Extension Services have partnered to create eXtension. This online portal seeks to deliver peer-reviewed information on the internet to the general public. A group from Rangelands West has been collaborating to create the eXtension Rangelands Web site with topics that mirror rangelandswest.org. Articles developed for eXtension seek to interpret peer-reviewed journal articles and Extension bulletins on a variety of rangeland-related topics. These articles are written in layman's terms and are peer-reviewed for accuracy. In an effort to make this scientifically based information readily available to the general public, eXtension focuses on optimizing its content for search engines such as Google, Bing, Yahoo, and others. In addition, the site has Frequently Asked Questions (FAQs) and Ask an Expert (AaE) modules. The FAQs provide peer-reviewed answers to common questions. The AaE provides a way for the public to ask questions and receive an answer from professionals in the field.

The Range Science Information System (RSIS) is an annotated bibliography of peer-reviewed literature. At this point, the included citations are related to domestic livestock grazing on public and private lands. The literature is selected to address the impacts of livestock grazing on riparian areas, weeds, wildlife, vegetation, soils, and other rangeland resources and issues, as well as the impact rangeland management has on livestock grazing. RSIS will eventually link to white papers that will synthesize the literature that is 
included within the database. Currently, the database is targeted at Montana, Idaho, and Wyoming issues, but much of the literature can be applicable to similar ecosystems. Besides keywords, the database is searchable by Major Land Resource Areas (MLRS) and vegetation types.

Reusable teaching/learning objects are being developed for Web delivery. These units range from small topics that can be used for a specific lecture to larger units that cover information, such as the World Rangelands Learning Experience (Wrangle) ${ }^{v i}$. The concept here is that these units would be available to anyone teaching a topic who needs some more localized or generalized information that they might not have in their particular region. The presentations will contain a variety of modules including PowerPoint presentations, notes, videos, and links to other resources. Although there will be a variety of ways to access these Objects, the Rangelands West Web site will be the primary portal.

\section{Using the Tools}

Each of the tools is designed to deliver different types of information that can be used in the classroom or in the field. All of the Web sites will be linked together, although we recommend that you use rangelandswest.org or globalrangelands.org as the main portal. In all cases, we are seeking to deliver the "best of the best" sources of information and interpretation. We are selective in the material that makes it into each of these tools.

The following are suggestions for ways to incorporate these tools into classroom and outreach teaching. If you are getting ready to make a presentation or give a lecture on a topic, you might either check the reusable teaching/learning object resources to see what others have done to get ideas of different ways to present the information, or select a specific presentation and give it. Because the concept behind a reusable teaching/learning object is that a presentation is already done, you can just use it as is or adapt it for your own class. As an example, if you are teaching a course in world rangeland ecosystems and needed to do a lecture on Oak Woodlands in California, the Wrangle Web site might be a place for you to look. On that site is a general description of oak woodlands, GigaPan pictures, descriptions of location and distribution, physical characteristics, plant and animal communities, vegetation dynamics, management issues and solutions, videos, literature cited, and other resources. The information will be in one place. Ideally, faculty from around the world will contribute information and resources to this site and make use of it in their own classrooms.

If you routinely assign homework, take-home exams, or papers, and expect students to find the relevant literature, then Rangelands West, Global Rangelands, eXtension, or RSIS will all be useful. RW and GR will provide a searchable database of vetted literature, access to full text articles from the Journal of Rangeland Management/Rangeland Ecology \& Management and Rangelands for articles older than 3 years, and all FAO rangeland-related publications. More content is being added

vi http://wrangle1.com. continuously. For a place to send students unfamiliar with the diversity of topics within rangeland ecology and management, eXtension is a starting place or to help them interpret some of the material they might find. You can also use the FAQs database to generate topics for class discussions or student assignments to test comprehension and ability to apply learned concepts in a real-world situation. Advanced classes or graduate students could write articles for eXtension similar to a traditional research paper that would undergo peer review before publication. RSIS is a place to send students to see how annotations can be done to view the literature on the specific topics it covers, or to scan the extensive annotations listing key learning and management strategies.

\section{Conclusion}

Do any of these tools offer anything that a student couldn't find through a search engine or a visit to the library? Perhaps in some cases, but most of the information can be found through such a search. What they do offer is a compact set of literature that has been vetted for scientific rigor and that have gone through some level of peer review. The material has been collected by state extension specialists and county educators/agents/advisors, subject matter librarians, rangeland scientists and managers, and college and university instructors.

Each of these tools can be useful to teachers and students. However, as with any tool, you need to understand what it was built to do, what its limitations are, and how to use it. All of our tools are being designed to provide ready access and ease of use. They will be constantly updated as new information becomes available and as technologies change. We encourage you to play with these tools, to let us know if something doesn't work (or better yet, if it does), and to join us on our quest to deliver quality information about our world's rangelands.

\section{Reference}

1. Hutchinson, B., J. Pfander, J. Tanaka, and J. Clark. 2011. Rangelands West/Global Rangelands, eXtension Rangelands, and the Range Science Information System: a suite of new Web resources. Rangelands 33(4):55-63.

Authors are Dept Head and Professor, Dept of Ecosystem Science and Management, University of Wyoming, Laramie, WY 82071, USA, jtanaka@uwyo.edu (Tanaka); Assistant Director, Agricultural Experiment Station, College of Agriculture and Life Sciences, University of Arizona, Tucson, AZ 85721, USA (Hutchinson); Research Scientist, Dept of Ecosystem Science and Management, University of Wyoming, Laramie, WY 82071, USA (FrakerMarble); Research Scientist, Animal \& Range Sciences, Montana State University, Bozeman, MT 59717, USA (Frost); Professor, Dept of Forest, Rangeland, and Fire Sciences, University of Idaho, Moscow, ID 83844, USA (Launchbaugh); and Cooperative Extension Specialist, Dept of Plant Sciences, University of California, Davis, Davis, CA 95616, USA (George). 